\title{
Pelvic floor examination performed by medical students: a model to obtain consent
}

This article was published in the following Dove Press journal:

Advances in Medical Education and Practice

\section{Swina Santhirakumaran Harkaran Singh Kalkat Vinay Jamnadas Sonagara}

Department of Undergraduate Medicine, Faculty of Medicine, Imperial College London, London, UK
Correspondence: Swina Santhirakumaran Department of Undergraduate Medicine, Faculty of Medicine, Imperial College London, Faculty Building, South Kensington, London, SW7 2AZ, UK Email swina.santhirakumaran13@imperial. ac.uk

\begin{abstract}
Student-led clinical examinations, including pelvic floor examinations, are an integral part of clinical training and can be beneficial to both students and patients alike. However, our experience and previous literature catalog numerous obstacles in obtaining consent for student-led pelvic floor examinations. Although some of these factors may not be modifiable, it is evident that efforts can be made to overcome those that are. An examination of these obstacles can help to provide a clear and succinct template to overcoming them: we propose a "5-Rs" framework that may bridge the apparent gap between the students' need to practice and obtain valid consent. Keywords: consent, teaching, pelvic floor examination
\end{abstract}

\section{Introduction}

In the learning and mastering of clinical examinations, there comes a point where trainees must transition from simulation exercises to live patients. ${ }^{1}$ This need, particularly in cases of pelvic floor examinations, can be asynchronous to the need to provide optimal care to the patient. ${ }^{1,2}$ Allowing an inexperienced medical student to learn by practice is not necessarily in the best interest of the patient involved but will be essential to the ongoing training that will result in benefit to future patients. ${ }^{1}$

Patients play an important role in medical education. The General Medical Council and university bodies have published guidelines outlining the importance of gaining informed consent. ${ }^{3,4}$ However, in our experience, there is nebulous practical advise on how these guidelines may be implemented in clinical practice. This, and the intimate nature of many of these examinations, results in medical students often not obtaining informed consent. ${ }^{5-8}$

Many students report that consent was not an important part of their clerkship, particularly in obstetrics and gynecology. ${ }^{5}$ Other studies have shown that within the medical team, senior doctors also often fail to introduce the medical student during the consent procedure, and in fear of being rejected, medical students are not forthcoming either. ${ }^{6,7}$ As a result, most patients are unaware that a medical student may be performing a procedure on them. This is a particular shame given the fact that active patient involvement in this process has actually proven to be beneficial to patients and most would be willing to allow medical students to participate, regardless of the student's inexperience. ${ }^{9,10}$

Given this, it is important for clinicians and medical students to recognize and overcome the common difficulties to gaining consent. Integration of robust models for gaining consent into medical education would facilitate this. 


\section{Challenges in obtaining consent}

There are several recognized challenges in gaining consent for pelvic floor examinations. It is important for clinicians and students alike to be aware of these challenges in order to address them while requesting consent. These challenges can be broadly divided into 1) patient, 2) student, and 3) staff factors (Figure 1).

Previous literature identified modifiable and unmodifiable factors, of which "male gender" and "previous negative experiences" were the most common unmodifiable factors. However, "staff" and "patient factors" such as unawareness of the student's role and concerns regarding privacy and confidentiality may be nullified with an effective framework for obtaining consent.

\section{A model to gain informed consent}

We propose a systematic "5-Rs model" that can be used in the clinical setting in conjunction with measures taken prior to the consultation to educate and inform patients. Taken together, we believe that these measures would bridge the gap between students' learning needs and patients' satisfaction and its induction would prove beneficial to patients, medical students, and medical professionals.

\section{Prior to the consultation}

At some teaching hospitals, appointment letters could state that medical students may be involved in patient care. ${ }^{14}$ Subsequently, if they would prefer not to have medical student involvement, patients can raise this on their arrival to the appointment. Such a system would allow the patient to be prepared and empower them to give or refuse consent confidently. Additional leaflets that outline the role of students within the consultation and highlight the mutualistic benefits of their presence could further improve the rate of consent. It should however be noted that distribution of this informa-

\begin{tabular}{|l|l|}
\hline Patient factors & $\begin{array}{l}\text { Previous negative experiences } \\
\text { Fear of pain during examination }\end{array}$ \\
& $\begin{array}{l}\text { Concerns about privacy during examination } \\
\text { Concerns about confidentiality of medical } \\
\text { information }^{13}\end{array}$ \\
\hline $\begin{array}{l}\text { Medical student } \\
\text { factors }\end{array}$ & Male gender ${ }^{11,12,14-17}$ \\
\hline Staff factors & $\begin{array}{l}\text { A negative introduction by doctors to the } \\
\text { patient }\end{array}$ \\
& $\begin{array}{l}\text { Lack of awareness of the need for medical } \\
\text { students to practice examinations } \\
\text { Lack of time to facilitate examinations in } \text { clinic }^{18} \\
\text { Protective midwives }\end{array}$ \\
\hline
\end{tabular}

Figure I Common difficulties in obtaining consent as identified in previous literature, with categorization of these difficulties into patient, medical student, and staff factors tion alone only surmounts to implied consent. ${ }^{16}$ Further steps should be taken immediately before the pelvic examination in order to ensure informed consent is gained.

\section{The 5-Rs model for obtaining consent}

We outline a simple and systematic model, the deployment of which, prior to the examination, could negate the common obstacles to gaining consent (Figure 2). In the early stages of training, the model should be led by the teacher with input from the student where appropriate. However, the relative roles of the student and teacher in carrying out the 5-Rs model should be adjusted according the confidence and competency of the student.

First, the "role" of the student should be made clear to the patient: their need for education and status within the medical team. The "reason" for the involvement of the student in the examination should be explained, for example, "in order to aid in the student's learning on how to perform examinations and to help in their future careers". In identifying the role and reason, the patient factors borne in concerns of privacy and confidentiality can be allayed. The "routine" of the examination, in the form of a step-by-step outline, should be explained to the patient. This can be later reinforced by the student for their learning purposes.

A recurring challenge in gaining consent remains patient anxiety regarding discomfort or pain. Therefore,

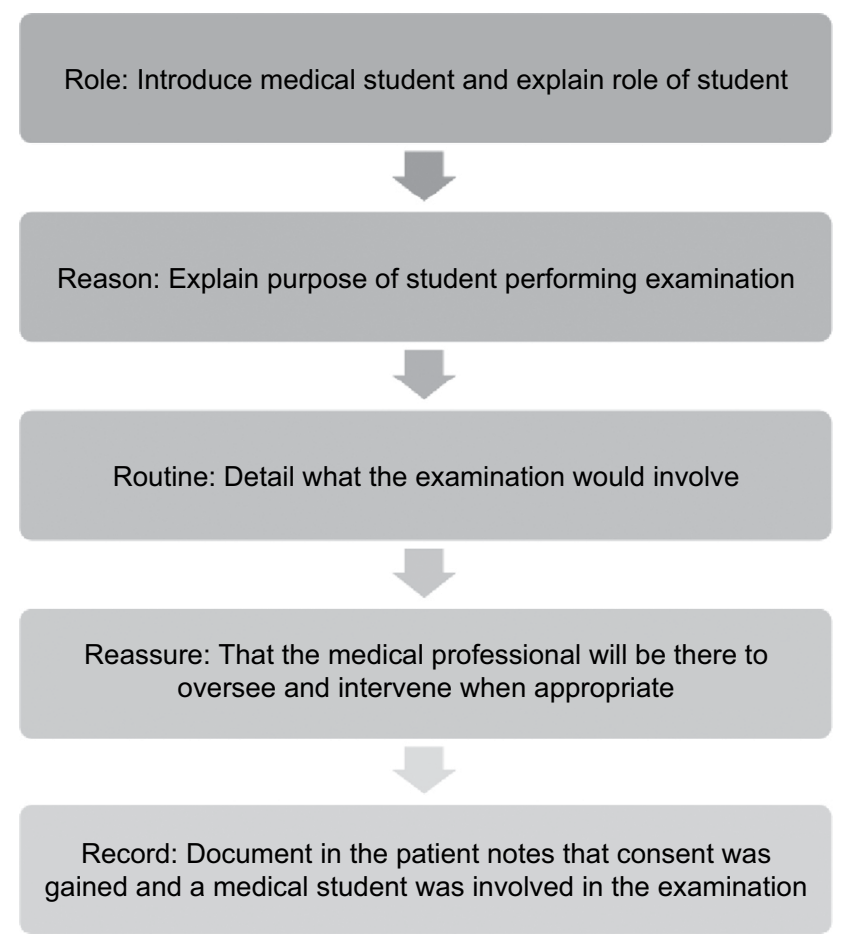

Figure 2 Schematic representation of the 5-Rs model. 
an important step is to "reassure" the patient, easing any concerns they may have and building on the rapport between patient and clinician. To further relieve any concerns or anxiety, it should be highlighted that the tutor will be present to oversee the examination, ensuring that it is safe and intervene if necessary. Additionally, the patient should be informed that they can ask to stop at any point and their decision will not affect the level of care that they receive. Once the patient has expressed consent to the examination, it would be appropriate to "record" in the patient notes that consent was gained and a medical student was involved in the examination. Adherence to the model can be achieved by integrating it into student teaching and providing posters outlining the protocol to be visible to staff. Although the 5-Rs model is intended for student-led pelvic floor examinations, it can be applied in gaining consent for other student-led intimate examinations such as breast, rectal, and male genital examinations.

\section{Conclusion}

Despite its foundational role in promoting patient autonomy and dignity, informed consent, particularly in student-led pelvic floor examinations, is not always obtained. While clinician teachers must ensure that medical students gain the required practical experience, their shared responsibility to the patient demands that improvements are made to current practices. Although some of the barriers that students face when obtaining consent may not be modifiable, novel strategies are required to mitigate those that are. We outline a 5-Rs model that may, in theory, be a feasible solution in overcoming some of these barriers. It directly addresses many of the factors that are highlighted in previous literature such as unawareness of medical student's role, previous negative experience and concerns about privacy, among others. Further studies are required, in the form of patient questionnaires, student and staff focus groups, and pilot studies, to validate such a model and observe its impact in practice.

\section{Disclosure}

The authors report no conflicts of interest in this work.

\section{References}

1. Ziv A, Wolpe PR, Small SD, Glick S. Simulation-based medical education: an ethical imperative. Acad Med. 2003;78(8):783-788.

2. Mankuta D, Shehadeh S, Kaitz M. Failure to obtain informed consent for intimate examinations by medical students. Open Access Journal of Gynecology. 2016;1(1):000102.

3. GMC. Clinical placements for medical students. GMC. 2011.

4. Bagg W, Adams J, Anderson L, et al. Medical Students and informed consent: A consensus statement prepared by the Faculties of Medical and Health Science of the Universities of Auckland and Otago, Chief Medical Officers of District Health Boards, New Zealand Medical Students' Association and the Medical Council of New Zealand. $N Z$ Med J. 2015;128(1414):27-35.

5. Ubel PA, Jepson C, Silver-Isenstadt A. Don't ask, don't tell: a change in medical student attitudes after obstetrics/gynecology clerkships toward seeking consent for pelvic examinations on an anesthetized patient. $\mathrm{Am}$ J Obstet Gynecol. 2003;188(2):575-579.

6. Akkad A, Bonas S, Stark P. Gender differences in final year medical students' experience of teaching of intimate examinations: a questionnaire study. BJOG: An International Journal of Obstetrics \& Gynaecology. 2008;115(5):625-632.

7. Omid A, Daneshpajouhnejad P, Pirhaji O, Students' M. Medical students' and physicians' attitudes toward patients' consent to participate in clinical training. $J A d v$ Med Educ Prof. 2015;3(1):21-25.

8. Broadmore J, Hutton JD, Langdana F. Medical students' experience of vaginal examinations of anaesthetised women. BJOG. 2009;116(5):731-733.

9. Howe A, Anderson J. Involving patients in medical education. BMJ. 2003;327(7410):326-328.

10. Koehler N, Mcmenamin C. Would you consent to being examined by a medical student? Western Australian general public survey. Med Teach. 2012;34(7):e518-e528.

11. Yang J, Black K. Medical students in gynaecology clinics. Clin Teach. 2014;11(4):254-258.

12. Rizk DE, Al-Shebah A, El-Zubeir MA, Thomas LB, Hassan MY, Ezimokhai M. Women's perceptions of and experiences with medical student involvement in outpatient obstetric and gynecologic care in the United Arab Emirates. Am J Obstet Gynecol. 2002;187(4):1091-1100.

13. Howe A, Anderson J. Involving patients in medical education. $B M J$. 2003;327(7410):326-328.

14. Carson-Stevens A, Davies MM, Jones R, Chik AD, Robbé IJ, Fiander AN. Framing patient consent for student involvement in pelvic examination: a dual model of autonomy. J Med Ethics. 2013;39(11):676-680.

15. Higham J, Steer PJ. Gender gap in undergraduate experience and performance in obstetrics and gynaecology: analysis of clinical experience logs. BMJ. 2004;328(7432):142-143.

16. O'Flynn N, Rymer J. Consent for teaching: the experience of women attending a gynaecology clinic. Med Educ. 2003;37(12):1109-1114.

17. Akkad A, Bonas S, Stark P. Gender differences in final year medical students' experience of teaching of intimate examinations: a questionnaire study. BJOG. 2008;115(5):625-632.

18. van den Einden LC, Te Kolste MG, Lagro-Janssen AL, Dukel L. Medical students' perceptions of the physician's role in not allowing them to perform gynecological examinations. Acad Med. 2014;89(1):77-83.

19. Bhoopatkar H, Wearn A, Vnuk A. Medical students' experience of performing female pelvic examinations: Opportunities and barriers. Aust N Z J Obstet Gynaecol. 2017;57(5):514-519. 
Advances in Medical Education and Practice

Dovepress

\section{Publish your work in this journal}

Advances in Medical Education and Practice is an international, peerreviewed, open access journal that aims to present and publish research on Medical Education covering medical, dental, nursing and allied health care professional education. The journal covers undergraduate education, postgraduate training and continuing medical education

including emerging trends and innovative models linking education, research, and health care services. The manuscript management system is completely online and includes a very quick and fair peer-review system. Visit http://www.dovepress.com/testimonials.php to read real quotes from published authors.

Submit your manuscript here: http://www.dovepress.com/advances-in-medical-education-and-practice-journal 